\title{
ADOÇÃO, ACOLHIMENTO E DEVOLUÇÃO: UM OLHAR E UMA ESCUTA A CRIANÇA
}

CLEIDE VITOR MUSSINI BATISTA UNIVERSIDADE ESTADUAL DE LONDRINA

LONDRINA, PARANÁ, BRASIL CLER.PSICO@GMAIL.COM

GILMARA LUPION MORENO UNIVERSIDADE ESTADUAL DE LONDRINA

LONDRINA, PARANÁ, BRASIL GILMARALUPION@HOTMAIL.COM 


\section{ADOÇÃO, ACOLHIMENTO E DEVOLUÇÃO: UM OLHAR E UMA ESCU- TA DA CRIANÇA E DO ADOLESCENTE}

Resumo: O artigo objetiva refletir sobre os impactos da devolução da criança e/ou do adolescente em processo de adoção. Trata-se de uma pesquisa bibliográfica com base na perspectiva da Psicanálise; nos Grupos de Estudos e Pesquisa; nos encontros e nas formações acerca da temática; e no acompanhamento de crianças e adolescentes acolhidos. Os resultados tendem a contribuir à preparação dos adotantes com vistas a minorar os casos de devolução.

Palavras-chave: Adoção; Acolhimento; Devolução; Psicanálise; Grupo de Estudos e Pesquisa.

\section{ADOPCIÓN, RECEPCIÓN Y REGRESO: UNA MIRADA Y ESCUCHA AL NIÑO}

Resumen: El articulo tiene como objetivo reflexionar sobre los impactos de devolver al niño y/o adolescente en el proceso de adopción. Esta es una investigación bibliográfica basada en la perspectiva teórica del Psicoanálisis; en grupos de estúdio, reuniones y capacitación sobre el tema; y el seguimiento de los niños y adolescentes recibidos. Los resultados son para ayudar a la preparación de los adoptantes con visitas para reducir los casos de devolución.

Palabras Clave: Adopción; Recepción; Volver; Psicoanálisis; Grupo de Estudios e Investigación.

\section{ADOPTION, FOSTERING AND RETURNING: VIEW AND LISTENING-IN TO THE CHILD AND ADOLESCENTE}

Abstract: The article aims to think over the impacts of returning children or adolescents in the process of adoption. This is a bibliographic research grounded on the theoretical perspective of Psychoanalysis; on Study and Research Groups; on meetings and training for the theme; and on monitoring children and adolescents who had been fostered. The results intend to contribute to the preparation of the adopters in order to reduce the cases of returning.

Keywords: Adoption; Fostering; Returning; Psychoanalysis; Study and Research Groups.

\section{INTRODUÇÃO}

Dar voz à criança à espera de uma família, escutá-la e ouvi-la, é de extrema necessidade na relação entre os adultos - psicólogos, assistentes 
sociais, promotores de justiça, juízes, cuidadores, pedagogos, professores, adotantes etc. - e a criança acolhida. D'Andrea (2012) nos presenteia com o conto "Martina e o Construtor de Pontes", em que uma menina de seis anos, com ajuda do Construtor de Pontes, escreve uma carta para seus futuros pais adotivos. "O objetivo da 'história' é colocar em evidência os pedidos, a curiosidade, os pensamentos, os medos, as dúvidas que uma menina com uma história vivida e 'à espera' de ser adotada pode viver e levar para a futura relação com os “novos pais'” (D’ANDREA, 2012, p. 27).

Na história, "[o] primeiro desejo que Martina exprime em sua mensagem é o de ser acolhida” (D’ANDREA, 2012, p. 15). Acolher, no sentido etimológico da palavra acolligere, significa receber, reunir, juntar, coletar, recolher. No caso de Martina, seus futuros pais deverão acolher o "[...] seu nome, seu corpo, sua história e sua cultura, que, na concretização da adoção, farão parte integrante da história e do patrimônio da família que a adotará" (D’ANDREA, 2012, p. 14). História não se apaga, cada um tem a sua, a criança adotada não pode ter violado o direito de ter preservada a sua origem, a sua história.

Conforme D’Andrea (2012, p. 15), “[a]dotar uma criança significa criar uma continuidade entre passado e presente, integrar pessoas e histórias do passado da criança com as do presente, aceitar essa maneira diferente de construir uma família”. No entanto, "[... e é necessário saber quais serão os desafios específicos que serão enfrentados sem correr riscos excessivos" (D'ANDREA, 2012, p. 15), como por exemplo, o relatado a seguir.

Era uma manhã, estava sentada à mesa do refeitório de um Centro de Educação Infantil (CEI), frente a uma pequena menina de 4 anos que estava a chorar. Com o intuito de acolhê-la, uma pergunta inevitável lhe foi feita: o que te faz tão triste e chorosa?

A pequena, entre lágrimas e soluços, achegou-se como que se adentrasse em meu corpo. Num gesto de acolhimento, acheguei-me também e envolvi-a em meus braços. Aconchegada, a pequena, em meio às lágrimas que escorriam pela sua face, agora não mais em prantos, falou baixinho que estava com saudades do irmão que vivia com ela no abrigo e que estava triste por ter sido trazida de volta da casa em que estava com ele.

Essa pequena falava de sua devolução ao abrigo e da permanência de seu irmão na casa dos adotantes. Então, ela faz uma série de indagações: será que não gostaram de mim, tia, só do meu irmão? Será que ninguém gosta de mim? 
Indagações invadem a pequena menina, a quem não invadiriam? Maria, nome fictício que usaremos para denominar a pequena, estava num abrigo há cerca de mais de um ano, o mesmo tempo que frequentava o CEl. Nesse período de acolhimento no abrigo, ela teve três experiências de devolução, sendo que, na última experiência, a família adotante acolhera seu irmão e a devolveu para o abrigo.

Esse pequeno recorte de uma cena cotidiana numa instituição de educação infantil leva-nos a pensar imediatamente em algum tipo de fracasso acerca da devolução: seria um fracasso da criança? Um fracasso dos procedimentos de adoção? Um fracasso dos pais adotantes? Não podemos afirmar, mas, em nossa experiência, todas as crianças que participaram do processo ligado à devolução viveram sentimentos de rejeição e de frustração.

Diante de um cenário no qual a adoção tem sido incentivada como possível solução, tantas vezes idealizada, para desordens sociais, como o abandono de crianças, ou até mesmo como forma de contornar as dificuldades com a procriação biológica, elencamos como questão-norteadora deste estudo: quais os impactos da devolução para o Judiciário de crianças e de adolescentes em processo de adoção?

Desse modo, este artigo objetiva refletir sobre os impactos das situações de devolução da criança e/ou do adolescente em processo de adoção nos seus desenvolvimentos psíquico e social. Já os objetivos específicos consistem em: refletir acerca das temáticas da adoção e do acolhimento institucional; discutir sobre as adoções e as devoluções antes e pós-adoção e sobre os possíveis sentimentos de rejeição e de frustração gerados nas crianças.

Quanto ao método, trata-se de uma pesquisa bibliográfica, com base na perspectiva teórica da Psicanálise; nos estudos realizados em um Projeto de Pesquisa e Extensão' sobre adoção e acolhimento institucional na escola, do Departamento de Educação da Universidade Estadual de Londrina (UEL); na participação das autoras nos encontros realizados pelo Instituto de Apoio à Adoção de Crianças e Adolescentes Trilhas do Afeto; e no processo de formação continuada de professores, gestores e demais profissionais que atuam junto às crianças acolhidas, por meio da Secretaria Municipal de Educação de Londrina (SME), a qual acompanha essas crianças em seu percurso desde a destituição familiar, o acolhimento institucional, o seu desenvolvi-

1 Projeto de Pesquisa e Extensão intitulado "Adoção e Acolhimento Institucional: uma proposta de formação continuada para professores e gestores da Educação Infantil e do Ensino Fundamental I de Londrina e região". 
mento escolar até a adoção delas.

No que se refere aos resultados, consideramos que este estudo pode lançar bases para que os profissionais do Judiciário discutam e reflitam sobre o tema aqui abordado, entre eles os de Psicologia, que lidam com as demandas de habilitação de adotantes. No mais, pode nortear práticas com vistas a minorar os casos de devolução de crianças em processo de adoção, como por exemplo, a obrigatoriedade dos futuros pais de participar efetivamente dos Grupos de Apoio à Adoção, os quais trabalham com afinco na preparação dos pretendentes e no acompanhamento das famílias pós-adoção.

\section{UM OLHAR E UMA ESCUTA PSICANALÍTICA A CRIANÇA}

\subsection{O que a Psicanálise pode nos ensinar acerca da adoção}

A adoção é uma via de filiação a qual muitos pais recorrem desde os tempos mais remotos. Seja por impossibilidade de gerar um filho, falecimento dos pais biológicos, casamento com cônjuge que já possui filhos, desejo pela adoção ou qualquer outro motivo, a adoção existe, faz parte da realidade e requer discussão.

As crianças e os pais estão inseridos em todas as esferas da sociedade, a qual, muitas vezes, demonstra não estar preparada para lidar com essa via de filiação, principalmente nas escolas, onde o tema "família" é trabalhado com as crianças e muitos professores demonstram não ter preparo para abordá-lo, principalmente quando um aluno foi adotado. Frequentemente relegada à filiação de segunda categoria, não verdadeira ou ato de caridade, o tema "adoção" necessita de visibilidade, de discussão, bem como de pesquisas na área.

A literatura referente a esse tema remete às experiências anteriores à adoção e dos vínculos iniciais entre a criança e os pais, sejam os adotivos, sejam os biológicos, conforme se nota no diálogo entre Martina e o Construtor de Pontes:

[... ] história de cada adoção começa com duas histórias de sofrimento: a sua que não tem mais pais; e a do casal, que não pode ter um filho próprio. São também duas histórias de separação: você foi separada de seus pais, que não estão mais aqui; mas eles também têm que se separar do sonho de gerar uma criança (D’ANDREA, 2012, p. 20). 
A criança, por encontrar-se em momento de extrema fragilidade, expressa-se pela necessidade de sobrevivência; o adulto, por desejar a adoção, expressa-se pela ansiedade e pela expectativa de que seus objetivos sejam atendidos. Se, por um lado, a criança que vive o caos desintegrador do pós-nascimento experimenta a necessidade de um ambiente acolhedor, por outro, o adulto, ao iniciar com a criança a formação dos primeiros vínculos, pode estar confuso por reviver a sua experiência primitiva das relações de objeto. Contudo, no conto, "Martina escolhe, naturalmente, como interlocutores privilegiados os seus futuros pais, que deverão ajudá-la a construir uma continuidade - uma ponte - entre o biológico e o afetivo, entre pai e mãe biológicos e pai e mãe afetivos" (D'ANDREA, 2012, p. 27).

A partir disso, algumas indagações se fazem pertinentes: qual o desejo de um casal na adoção de uma criança? Que lugar essa criança pode vir a ocupar no desejo dos pais adotantes?

A partir dessas indagações, intenta-se compreender os impactos das primeiras inscrições no psiquismo das crianças, por entendermos que muitas delas foram geradas por pessoas que não queriam ou não desejavam, não podiam ou que, pela vulnerabilidade social em que se encontravam, não conseguiam cuidar de seus próprios filhos e, consequentemente, acabariam por romper drasticamente - e, em muitos casos, precocemente - os vínculos iniciais do desenvolvimento.

O estudo aqui apresentado fundamenta-se na teoria psicanalítica, especialmente de autores que dedicaram estudo às primeiras inscrições psíquicas na constituição do sujeito humano, tais como Freud, Winnicott e Dolto. Na perspectiva teórica da Psicanálise, parte-se da compreensão de que todo sujeito, com vínculo biológico ou adotivo juridicamente, necessita ser adotado no desejo do par parental que o escolheu, elegeu-o e o nomeou como filho. A saber, de acordo com o artigo 41 do Estatuto da Criança e do Adolescente (ECA), adoção é o ato de atribuir a condição de filho ao adotado, que gozará dos mesmos direitos e deveres, inclusive relativos à sucessão, e será desligado de qualquer vínculo com os pais e parentes biológicos, salvo se houver impedimentos matrimoniais (BRASIL, 1990).

Não temos, aqui, a pretensão de preencher as lacunas a respeito desse tema, muito menos esgotá-lo, mas colaborar para seu entendimento, contribuindo para os processos dos gestores de instituições dedicadas ao cuidado da infância, bem como dos pais e dos professores.

Nesse contexto, o enfoque psicanalítico considera que as primeiras ins- 
crições no psiquismo pueril são marcas que se situarão na criança durante toda a sua existência, ainda que ela seja retirada de seus progenitores muito precocemente. Contudo, essa condição não inviabiliza que novas inscrições possam dar significado e ressignificar a psique infantil e, quando positivas, dão condição para um desenvolvimento saudável e criativo.

Em nossa sociedade, assistimos à forma como a relação mãe/bebêé muito enfatizada e tida como imperativa para se avalizar um desenvolvimento infantil saudável. Segundo Winnicott (1956/1978), a mãe se constitui como a pessoa mais adequada para cuidar do seu bebê e é ela que pode atingir um estado de preocupação materna primária, fornecendo um setting no qual a constituição do bebê possa se manifestar, juntamente a suas tendências desenvolvimentais, enquanto este pode experimentar um movimento espontâneo e dominar as sensações apropriadas a essa fase inicial de vida.

Essa mãe é capaz de sentir como se estivesse no lugar do bebê e, desse modo, corresponder as suas necessidades, as quais, inicialmente, são corporais e, gradualmente, tornam-se necessidades do ego, à medida que, a partir da elaboração imaginativa da experiência física, surge a experiência psicológica.

No entanto, Winnicott (1956/1978) postula que uma mãe adotiva, ou qualquer mulher que possa ficar doente no sentido de apresentar uma preocupação materna primária, pode ser capaz de se adaptar suficientemente bem, por ter alguma capacidade de se identificar com o bebê. Nesse sentido, um ambiente favorável nos primórdios de vida do bebê permite que este comece a existir enquanto sujeito singular, a ter experiências, a construir um ego pessoal, a dominar as pulsões e a enfrentar todas as dificuldades inerentes à vida.

A criança, coloca Dolto (1989), no ato de sua adoção, é obrigada a recomeçar todo o seu trabalho psíquico, de estruturação simbólica, que faz a criança ter de começar da "estaca zero", de produzir uma espécie de "luto" dos pais de nascimento ou da instituição a qual pertencia. Ademais, a criança precisa ter um tempo para compreender essa outra língua, a dos pais adotantes, adaptar-se a ela, e ela própria adotar seus novos pais, autorizando-se a ser filha de seus pais adotantes.

Contudo, também é sabido que frequentemente prevalece,

[...] no espírito dos pais adotantes em dificuldade, um desmentido violento do valor suposto dos genitores de sua criança; o que tende a instaurar uma espécie de efeito narcísico negativamente [...] 
entre os "abandonadores indignos" e os "ladrões de crianças", como se esses últimos tivessem tanta necessidade de denegrir os hipotéticos genitores [...] que experimentam, eles próprios, uma incapacidade subjetiva de exercerem sua "parentalidade" (PENOT, 1992, p.125).

Podemos afirmar, então, que o casal parental estaria tomado pela relação imaginária que acabara mantendo com os pais de nascimento, como se tivessem que destruir essa imagem de origem para se afirmarem como pais "verdadeiros" perante sua criança.

O "mal-estar" no mundo dos adultos, bem como a sintomática enviada pela criança em resposta ao (des)encontro entre mãe-pai-criança adotiva poderiam, dessa maneira, embaraçar qualquer possibilidade de emergência de um sujeito. Nessa engrenagem, um projeto de trabalho com a criança deveria traçar um caminho, posto desde a alienação da criança ao discurso do desejo materno - operado pela mãe adotante - até a separação - operada pela castração simbólica ${ }^{2}$-, representada pelo discurso paterno lembrado, por essa criança, por meio da voz do pai adotivo. Ao atravessar esse caminho, a criança pode assumir um lugar de pertença na família adotante, de filiação ao mundo humano.

Pode-se inferir, assim, que uma história de vida só poderá cultivar laços se a verdade puder encontrar seu justo lugar. Se não puder encontrar vias simbólicas de realização, o desejo enlouquece e conduz corpo, afeto e linguagem a ligações muito perigosas e desastrosas.

Dessa maneira, a partir do levantamento dos referenciais bibliográficos psicanalíticos acerca da adoção, entendemos que as primeiras inscrições deixadas na criança por meio da relação estabelecida com a figura materna deixarão marcas no seu psiquismo, as quais influenciarão na estruturação da sua personalidade. Essas marcas são sinais que poderão denotar atitudes e comportamentos positivos e/ou negativos, ou seja, as primeiras inscrições deixadas na mais tenra idade admitirão marcas mnêmicas de odor, textura, forma, temperatura, paladar, entre outras e, mesmo que a criança passe um

2 A castração somente é possível e exerce seu efeito no momento em que a instância paterna produz a ruptura da relação dual entre a mãe e a criança ou, em outros termos, a significação do falo apenas tem efeito quando o significante nome-do-pai passa a ocupar o lugar que antes era ocupado pelo desejo da mãe. Para Lacan (1995, p. 233), “[...] a intervenção do pai introduz aqui a ordem simbólica com suas defesas, o reino de lei [...]. O pai é aquele com quem não há mais chance de ganhar, senão aceitando tal e qual a divisão de apostas". 
curto período de tempo com a mãe biológica, as primeiras vivências poderão influenciar no posterior desenvolvimento psíquico da criança.

Por outro lado, as vivências posteriores, estabelecidas na relação com os pais adotivos, possibilitarão o agravamento, a manutenção e/ou a ressignificação dessas primeiras vivências, de acordo com o tipo de vinculação que será estabelecido entre criança e pais adotivos, isto é, pode ser marcado por uma oportunidade de a criança estabelecer novos vínculos afetivos e esses serem reparadores de possíveis experiências traumáticas vivenciadas. A história anterior à adoção é parte integrante da identidade do filho adotado, logo, "[...] a tarefa dos pais adotivos está em unir esta história com aquela que a nova família viverá junto, precisa soldar a experiência não convivida" (D'ANDREA, 2012, p. 78-79).

Os pais adotivos, assim como os pais biológicos, devem ser capazes de exercer uma apropriação real sobre o filho, haja vista que assumem "adotar" essa criança no sentido mais amplo do termo, ou seja, aceitam-na para lhe oferecer todos os cuidados e assumem o papel de pais e provedores. Como bem define Levinzon (2004, p. 25), “[...] toda filiação é, antes de tudo, uma adoção".

Assim, a titulação de genitores não garante aos pais a qualificação para constituírem uma verdadeira parentalidade, ela se dá somente quando adotam efetivamente a criança que lhes é incumbida, por meio da gestação ou da adoção, sendo que a segunda também se traduz por uma gestação psicológica. Todos os filhos, independentemente da via de filiação, precisam ser adotados, desejados, percebidos e possuidores de um lugar na família.

Todos os filhos são biológicos e todos os filhos são adotivos. Biológicos, porque essa é a única maneira de existirmos concreta e objetivamente; adotivos porque é a única forma de sermos verdadeiramente filhos. A real e autêntica parentalidade é a afetiva. $O$ processo biológico é apenas o conduto para que se possa amar e, portanto, transformar o puramente biológico em afetivo (SCHETTINI FILHO, 2004, p. 43).

Cabe salientar, contudo, que a adoção judicial implica algumas peculiaridades que devem ser levadas em conta inicialmente e durante o processo de desenvolvimento da criança. Dessa forma, os pais devem buscar conhecer seus desejos internos de exercer uma função parental, identificando suas reais possibilidades de se doarem efetivamente a uma criança que possui uma história antes da adoção e que, nela, necessita ser cuidada e amada 
por uma nova família, a qual, progressivamente, assumirá os papéis e os registros dos primeiros cuidadores, tornando-se a provedora de novas significações e de ressignificações no psiquismo infantil.

O desejo fundamental de uma criança que vive na condição da pequena Maria e da Martina "[...] é o de ser acolhida pelos pais adotivos: de voltar a ser filha. É o mais humano e universal dos desejos. Não é por acaso que o direito à família está entre os 'direitos fundamentais dos menores' reconhecidos pela Convenção Internacional da ONU” (D’ANDREA, 2012, p. 82).

Considerando que a Psicanálise se debruça sobre a formação da subjetividade do sujeito, postula-se que é necessário o desejo de nomear um filho, pois, caso contrário, há uma série de impasses que podem repercutir em efeitos devastadores e traumáticos sobre a criança no decorrer de sua vida. Nessa perspectiva, a adoção é uma possibilidade de o sujeito reconstruir novos laços afetivos e de ter lugar marcado em sua história familiar.

\subsection{Devolução: uma discussão que se faz urgente}

"Acolher uma criança que se submeteu a uma separação ou um abandono significa, de fato, estar aberto ao sofrimento, para poder compartilhar o prazer da sua chegada" (D’ANDREA, 2012, p. 87). Os adotantes que, por acaso, não tenham superado seus traumas, seja da esterilidade, ou do filho biológico que não "vingou", ou mesmo que não conseguiram se afastar o bastante do filho idealizado para conviver com o filho real, encontrarão "[...] maior dificuldade para construir uma autêntica relação acoIhedora” (D'ANDREA, 2012, p. 87).

Para o autor, "[...] o filho adotado, de fato, percebe, por meio de uma série de mensagens não verbais, desde os primeiros momentos do encontro, a disponibilidade de ser acolhido" (D’ANDREA, 2012, p. 87). Gestos, olhares, expressões, tons de voz dizem mais que as palavras, "[...] são canais por meio dos quais chega uma mensagem de aceitação ou não aceitação" (D’ANDREA, 2012, p. 87). A mensagem, então, pode ser de rejeição, nos casos mais extremos, chegando à devolução, o que gera na criança consequências destrutivas.

Entendemos que a devolução de crianças e de adolescentes durante o estágio de convivência ou mesmo após a adoção de fato demonstra ser a "ponta de um iceberg" de um sistema de (des)proteção social muito maior. Nesse sentido, nos grupos de estudos realizados com profissionais de di- 
ferentes áreas - Educação, Psicologia, Direito e Assistência Social -, as reflexões passaram por várias questões. Dentre elas, a ocorrência da violação de direitos, tais como: a situação de acolhimento institucional; a separação da criança de sua família de origem; o processo de destituição do poder familiar; as adoções e as devoluções antes e pós-adoção; as não-adoções tardias, entre outras.

Ressaltamos que a adoção de crianças tem caráter irrevogável, ou seja, adotar uma criança tem as mesmas prerrogativas de se ter um filho biológico e os mesmos deveres perante a lei. Em termos legais, a adoção, depois de concluída, é irreversível. Para evitar que haja arrependimento por parte dos pais adotivos e da criança, o Estatuto da Criança e do Adolescente (ECA) prevê um período de adaptação, a fim de que seja estabelecido o contato entre as partes e avaliadas as compatibilidades (BRASIL, 1990).

A saber, a maioria das devoluções acontece nesse estágio, e podemos ressaltar que não deixam de ser menos traumáticas para a criança. Ainda assim, existem casos em que a adoção é concluída e somente então a criança é devolvida para a instituição de origem. Quando isso acontece, a justiça busca por parentes da família adotiva que estejam interessados em obter a guarda provisória daquela criança. Caso não existam, ela é encaminhada a um abrigo, onde permanecerá até que seja adotada novamente.

Vemos, então, que o caráter de irrevogabilidade não é suficiente para impedir que rompimentos de vínculo nefastos possam ocorrer. É, porém, na esfera mesma do "cunho afetivo" que de fato ocorrem dramáticas situações de devolução de crianças adotadas.

Nos grupos de discussão, entendemos que era preciso refletir sobre as situações de devolução de crianças e de adolescentes ao Judiciário, tendo em vista que as devoluções antes e pós-adoção causam graves impactos para a criança e/ou o adolescente no que tange aos aspectos emocionais, na construção de sua identidade, na sua relação com o mundo, nas futuras relações interpessoais, entre outros. Segundo Ghirardi (2008), ao se estabelecer a ruptura do laço afetivo a partir da devolução, tem-se uma experiência reeditada pela criança em relação a sua história de abandono.

Ainda nesse grupo de discussão, foi trazida a ideia de "coisificação da criança" a ser adotada. Nessa direção, em relação aos pretendentes, a adoção, esse compromisso deve ir além daquele que se assemelha ao de um "consumidor" que busca na loja um "objeto/brinquedo" (bem de consumo) e que, se não gostar, poderá devolvê-lo. Todavia, podemos pensar que é 
bastante representativa a ideia de que a criança pode figurar como "objeto", como "coisa", não sujeito, nos processos de adoção-devolução.

Cabe refletir, nessa perspectiva, acerca da sociabilidade na contemporaneidade, em que as relações interpessoais ocorrem numa lógica semelhante à dos bens de consumo, ou seja, quando algo já não nos interessa, ficou obsoleto ou apresenta algum defeito, é rapidamente descartado ou trocado.

Nessa lógica, testemunhamos que a criança adotada se torna "coisa" e, "coisificada", passa a ser tratada como um objeto nas mãos de adultos que têm o poder de decisão sobre a sua vida. A criança adotada, colocada nesse cenário "mercadológico", parece se tornar apenas um objeto ou uma mercadoria, que, apesar de ser "isto" (educada, por exemplo) ou "aquilo" ("bonitinha") na visão dos pais adotantes, tem defeitos: bater nas crianças das visitas que frequentam a casa, ir mal na escolar, ter se metido em confusão, entre tantas outras situações que acometem qualquer criança. Assim sendo, como em um processo em que a mercadoria apresenta um problema, um defeito, os clientes - os pais adotivos - devolvem-na.

É sabido que ser reconhecido e aceito é a base da constituição do ser humano e, quando essa estrutura não é estabelecida, com grande frequência há o comprometimento da identidade e da autoestima. Além disso, é comum o comportamento agressivo e o comprometimento do desempenho escolar e da sociabilidade. Segundo Ladvocat (2005, p. 13 apud SOUZA, 2012, p. 25):

Geralmente, a devolução ocorre nas adoções tardias, muito mais pelas dificuldades dos pais no período de adaptação, dificuldades essas embasadas nas crenças e mitos sobre a vida pré-adotiva das crianças e pelo peso da genética herdada. [...] A família geralmente atribui determinados comportamentos às histórias de vida difíceis de serem esquecidas. Nestes casos a passagem do abrigo à casa da família deve ser acompanhada mais de perto pelos profissionais da Vara da Infância. [...] As motivações dos pais não foram devidamente conscientizadas na época da opção pela adoção e encontram barreiras da aceitação.

Como em muitos casos, os pais devolvem a criança simplesmente. Eles esquivam-se do compromisso assumido, colocando a cidadania daquele que seria seu filho num patamar social de "devolvido(a)". Nessas circunstâncias, os adultos não souberam lidar com as dificuldades e com as diferenças, então é mais fácil devolver e desistir da paternagem (SOUZA, 2012).

Para a autora, o retorno ao abrigo após a devolução deve ser visto como 
uma dupla frustração, em que a criança sente-se culpada por não ter dado certo o convívio com a família e, ao mesmo tempo, padece pela vergonha de ter que retornar para o acolhimento institucional após um "fracasso". Ademais, "tem uma tripla perda: da esperança, da família e pelo fato de ficar estigmatizada, uma vez que a devolução constará em seu histórico e poderá prejudicar uma próxima adoção" (SOUZA, 2012, p. 11).

Souza destaca, ainda, que quem supostamente tem maturidade são os adultos, sendo, portanto, os responsáveis pelo sucesso da adoção da criança maior. Essas pessoas que "devolvem" são cruéis? Egoístas ou vítimas? Como entender? Terão que reconstruir suas vidas, mas são adultos. Livram-se do "incômodo" gerando problemas e confusões. O que será da criança? (SOUZA, 2012).

Nas discussões e nas leituras realizadas nos grupos de estudos, entendemos que, para reverter esse quadro, é preciso tempo, atendimento especializado, amor e acolhimento, a fim de que seja devolvida à criança a sensação de enraizamento, de pertencimento. Isso porque, pela segunda vez (no caso da pequena Maria, pela terceira vez), "[...] Ihe é negado o direito de existir como filho; frustra o seu desejo de pertencimento; não a faz se sentir aceita pelo que realmente é; impede-a de se realizar" (D'ANDREA, 2012, p. 87).

De acordo com Freud (2010) e Lacan (1987), o dito de amor desses pares parentais está referido à própria ferida narcísica de cada um deles, assim como o anseio subjetivo de completude, na relação particular com a castração. O desejo de adoção, seja o filho biológico ou não, passa pelas idealizações imaginárias de cada um frente ao falo. Como Freud nos coloca, não há garantias para o sujeito advindo pela via biológica, tampouco há para o sujeito adotado; também não há fórmulas que possam designar ou determinar que um sujeito seja filho desses ou daqueles pais, mas um desejo que o nomeie como filho. Nessas buscas do sujeito, "[...] cada um tem que descobrir a sua maneira particular de ser feliz” (FREUD, 2010, p. 41).

Pensando assim, a adoção começa com a fantasia de um filho ideal, mas a criança é real, cheia de hábitos e costumes, principalmente as mais velhas. No diálogo do Construtor de Pontes com Martina sobre a sua história passada, ele diz: "[...] os seus pais não poderão acreditar que você nasce no momento em que a adotarem. Você é uma menina verdadeira: você é Martina, não é o menino que talvez eles ainda tenham na cabeça, que é um menino que não existe". Martina compreende e responde: "Eu sou uma 
menina de seis anos. O 'outro' teria sido um bebê. Podia também ser um menino! [... Mas não devem tentar me encaixar no pedaço que falta do quebra-cabeça deles... mas também, não conseguiriam!" (D’ANDREA, 2012, p. 59).

Assim, a adoção "[... ] leva as pessoas envolvidas a encontrar uma parte 'diferente' de si mesmos - inicialmente vista como ameaçadora (a esterilidade para o casal, o abandono para a criança) -, acolhê-la e a integrá-la à própria vida, até reconhecê-la como um recurso e fonte vital" (D'ANDREA, 2012, p. 16). Tem-se o que espera toda criança adotada: "que seus pais saibam aceitar o desafio dessa transformação que levará um casal e uma criança a passarem de desconhecidos a uma família" (D'ANDREA, 2012, p. 16). No conto, o Construtor de Pontes “[...] consegue explicar a Martina o mistério da adoção por meio de uma metáfora, a do quebra-cabeça incompleto. [... ] O segredo, então, a magia da adoção está no reencontrar juntos as peças que faltam para fazer renascer a vida" (D'ANDREA, 2012, p. 20).

Nessa trilha de estudos e de pesquisas, podemos afirmar e elucidar que a adoção tende ao fracasso quando há busca de reparação sem o trabalho de perlaboração da ferida narcísica, no sentido de separar o desejo de filho do desejo de procriar. Muitas vezes, a vulnerabilidade de alguns casais afetados narcisicamente pela impossibilidade de gerar pode constituir obstáculo à nova filiação, caso não tenha sido trabalhado o luto decorrente da infertilidade, como destaca Queiroz (2012). De acordo com essa autora, os adotantes que não conseguem elaborar a dificuldade de filiar biologicamente findam por colocar a adoção sob as condições de subfiliação, de modo que a criança venha apenas como forma de amenizar a ferida narcísica.

Ainda que o desejo de adotar venha como suplência para reparar questões narcísicas arcaicas presentes na história dos adotantes, dificulta, assim, a disponibilidade psíquica para acolher a criança. Isso também acontece quando não há operatividade da função paterna - ou seja, quando a mãe não faz do pai, posição metafórica, aquele que sanciona, por sua presença, a existência da lei - e, enfim, quando a sombra do passado das crianças recai sobre os novos pais (LACAN, 1999).

Ressaltamos que, para o sujeito, não há garantias, seja biológico ou adotivo. Nesse sentido, não é possível prever o "sucesso" ou o "insucesso" de uma adoção, mas se pode escutar, nos discursos dos que se candidatam, o desejo anônimo ou nomeado que perpassa a questão de adotar um filho. Portanto, a adoção é uma forma de o sujeito (re)construir e (re)inventar 
sua trama familiar, conforme o que contingencialmente lhe foi ofertado em uma decisão judicial. Trata-se de o sujeito poder fazer do contingencial um feliz encontro.

Ademais, faz-se preciso que haja espaço de acolhimento nas instituições destinadas à adoção durante o percurso em que os postulantes tramitem nesse interesse e posteriormente à adoção, ou seja, grupos de pré-adoção e de pós-adoção.

Salientamos, aqui, que existe grande demanda de fala, mas é preciso e urgente uma escuta. É necessário que os grupos de adoção, juntamente aos profissionais de Psicologia, ofertem espaço de acolhimento às demandas dos postulantes à adoção para expressarem desejos, anseios, dúvidas, fantasias, idealizações e para se indagarem em relação à realidade mais próxima da verdade: qual o desejo de um casal pela adoção de uma criança? Que lugar essa criança pode vir a ocupar no desejo dos pais adotantes? O que se adota junto a um filho?

Nos casos em que se percebem dificuldades (no desejo, na fantasia, na idealização, nas relações conjugais, na condução do processo, no entendimento sobre a adoção, entre tantas outras questões), é necessário investir, de diferentes formas, para um melhor preparo dos adotantes. Desse modo, como no conto, parafraseando D'Andrea (2012), o Construtor de Pontes - leia-se assistentes sociais, psicólogos jurídicos, membros dos Grupos de Apoio à Adoção, promotores e juízes - pode consertar pontes, reconstruir estradas, descobrir atalhos para fazer pessoas que se perderam de vista se encontrarem, adotarem-se.

\section{CONSIDERAÇÕES FINAIS}

Como vimos ao longo do texto, os impactos das situações de devolução na vida das crianças são nefastos, o gosto amargo do abandono ou da separação é ainda maior, a desconfiança nos adultos ganha maior proporção, deixar-se envolver numa nova tentativa de adoção fica ainda mais distante, os desenvolvimentos emocional, social e cognitivo dessas crianças são comprometidos. Assim sendo, precisamos trabalhar para garantir a essas crianças o que lhes é de direito: ter uma família, ser filho.

Ao refletir acerca dos fatores que colaboram para a devolução de crianças antes e pós-adoção - objetivo do nosso estudo -, podemos salientar que a paternidade ou a maternidade biológica pode até acontecer por "acidente", como alegam muitos pais e mães. No entanto, a adoção é uma escolha 
que deve ser planejada e refletida, e os adultos envolvidos carecem de preparo para essa importante forma de filiação.

É preciso entender que a adoção se relaciona com diferentes sujeitos, ou seja, tem a ver com uma criança e sua biografia, sua história de vida e com adultos que também têm as suas histórias peculiares (futuros pais, avós, tios, irmãos, primos, entre outros envolvidos no processo). Os pretendentes, todos, devem se preparar para o desafio da adoção, entendendo a preparação como uma forma de fortalecimento, não como uma perda de tempo.

A legislação já preconiza o preparo pré-adoção (psicossocial e jurídico), o que o Grupo Trilhas do Afeto $^{3}$ vem realizando há anos. Então, acreditamos na importância de buscar qualificar esse trabalho, por entendermos que os pretendentes também têm histórias relacionadas a dores não superadas, tais como: situações de infertilidade, de luto, de aborto, idealização do filho adotivo, entre tantas outras.

Enfim, entendemos que a devolução pode ter uma relação direta com o processo de habilitação e de avaliação dos pretendentes, não no sentido de dizer que foi feita uma boa ou má habilitação. Afinal, não basta apenas ter condições objetivas (materiais), pois não se trata de um aspecto tão pragmático nem sequer basta atribuir culpa a quem quer que seja. Compreendemos que se deve explicitar a necessidade de que as avaliações sejam criteriosas, com vistas a inverter o modelo preestabelecido de perguntas e respostas, na direção de uma maior capacidade de escuta e de percepção do não dito.

Assim, enfatizamos que criança não é objeto nem brinquedo. Portanto, não pode ser devolvida porque não soube segurar a caneca e derramou o leite; por ter pegado a canetinha e escrito ou desenhado por toda a parede da casa; por ter brigado com o irmão; por ter chorado muito; por não parar quieta e querer atenção a todo momento, ou seja, porque não atende às expectativas dos adultos.

As devoluções precisam ser evitadas ao máximo e, quando isso não for possível, devem ser muito bem trabalhadas. Além disso, os adultos devem ser responsáveis - bem como responsabilizados - por seus atos. Eles são as pessoas que devem estar preparadas para o enfrentamento da vida real, que se processa no cotidiano com a criança, também real, não mais imaginária e ideal. Acreditamos e apostamos no trabalho com os pretendentes à 
adoção para que possam preencher o berço vazio com uma criança e expectativas reais.

\section{REFERÊNCIAS}

BRASIL. Lei no 8.069, de 13 de julho de 1990. Dispõe sobre o Estatuto da Criança e do Adolescente e dá outras providências. Brasília: Senado Federal, 1990. Disponível em: http:// www.planalto.gov.br/ccivil_03/leis//8069.htm. Acesso em: 24 abr. 2020.

D'ANDREA, A. Tempo de espera: como vivem as crianças, o casal e os trabalhadores sociais à espera da adoção. Tradução de Luci Moreira da Costa. São Paulo: Instituto de Terapia Familiar de São Paulo - ITFSP, 2012.

DOLTO, F. Dialogando sobre crianças e adolescentes. Campinas (SP): Papirus, 1989.

FREUD, S. Além do Princípio do Prazer. [originalmente publicado em 1920]. In: FREUD, S. Edição Standard das Obras Completas de Sigmund Freud. Rio de Janeiro: Imago, 1969, p. 11-85. v. 18.

FREUD, S. O mal-estar na civilização. [original publicado em 1930]. In: FREUD, S. Obras completas. São Paulo: Companhia das Letras, 2010, p. 13-123. v. 18.

GHIRARDI, M. L. A. M. A devolução de crianças e adolescentes adotivos sob a ótica psicanalítica: reedição de histórias de abandono. 2008. Dissertação (Mestrado em Psicologia) - Instituto de Psicologia, Universidade de São Paulo, São Paulo, 2008.

LACAN, J. O Seminário. Livro 4: A relação de objeto. [original publicado em 1956-57]. Rio de Janeiro: Jorge Zahar, 1995.

LACAN, J. O Seminário. Livro 5: As formações do inconsciente. [original publicado em 1957-1958]. São Paulo: Jorge Zahar, 1999.

LACAN, J. Os complexos familiares na formação do indivíduo: ensaio de análise de uma função em psicologia. Rio de Janeiro: Jorge Zahar, 1987.

LEVINZON, J. K. Adoção. In: LEVINZON, J. K. Coleção Clínica Psicanalítica. São Paulo: Casa do Psicólogo, 2004, p. 11-85.

PENOT, B. Condição narcísica e emergência do sujeito - sobre a patologia adolescente de alguns adotados. 1992. Tradução de M. R. Oliveira. In: Corrêa, A. I. (Org.). Mais tarde... é agora! Ensaios sobre a adolescência. Salvador: Algama, 1996, p. 119-137.

QUEIROZ, E. F. O “romance familiar” na adoção. In: QUEIROZ, E. F.; PASSOS, C. M. (Orgs.). A clínica da adoção. Recife: Ed. Universitária da UFPE, 2012, p. 103-116.

SCHETTINI FILHO, Luiz. Adoção: origem, segredo e revelação. Recife: Bagaço, 2004.

SOUZA, H. P. Adoção tardia: devolução ou desistência do filho? A necessária preparação para adoção. Curitiba: Juruá, 2012.

WINNICOTT, D. W. Os bebês e suas mães. São Paulo: Martins Fontes, 1896/1971.

WINNICOTT, D. W. Preocupação materna primária, 1956. In: WINNICOTT, D. W. Textos selecionados: da pediatria à psicanálise. Rio de Janeiro: Francisco Alves, 1978, p. 491-498. 
CADERNOS DE COMUNICAÇÃO

UNIVERSIDADE FEDERAL DE SANTA MARIA

WINNICOTT, D. W. Tudo começa em casa. São Paulo: Martins Fontes, 1986/1971.

Rev. Cad. Comun., Santa Maria, v.24, n.2, art 6, p.18 de 19, Mai/Ago.2020 


\section{Cleide Vitor Mussini Batista}

Pós-Doutora em Psicologia pela USP e em Psicanálise pela UFPB. Docente do Departamento de Educação da UEL. Psicanalista. Membro da Associação Livre-Psicanálise em Londrina $(A L P L)$. Membro do Instituto de Apoio à Adoção de Crianças e Adolescentes Trilhas do Afeto.

E-mail: cler.psico@gmail.com

\section{Gilmara Lupion Moreno}

Doutora em Educação pela Universidade de São Paulo (USP). Docente do Departamento de Educação da Universidade Estadual de Londrina (UEL). Membro do Instituto de Apoio à Adoção de Crianças e Adolescentes Trilhas do Afeto. E-mail: gilmaralupion@hotmail.com 